\title{
Simulation And Hardware Analysis Of Three Phase PWM Rectifier With Power Factor Correction
}

\author{
P.Manikandan ${ }^{1}$, SP. Umayal ${ }^{2}$ A. Mariya Chithra Mary ${ }^{3}$ M.Ramachandran ${ }^{4}$ \\ Assistant professor Department of Electrical and Electronics Engineering, Sree Sowdambika College of \\ Engineering, Aruppukottai. ${ }^{1,3}$ Professor Sethu institute of technology, Kariaapatti. ${ }^{2}$ PSN college of engineering \\ and technology, Tirunelveli. ${ }^{4}$
}

\begin{abstract}
Three-phase controlled rectifiers have a wide range of applications such as motor control in industries, dc drives, cycloconverters etc. They are used for electro-chemical process, many kinds of motor drives, traction equipment, controlled power supplies, and many other applications. The main aim of this paper is to design the three phase PWM rectifier and analyze its performance. The rectifier is designed to convert input ac power into intermediate dc power. This power conversion is done at unity power factor viewed from the supply mains. The advantage of this system is it also improves the power quality. This improved power factor improves/modifies the wave shape of line current close to sinusoidal and reduces the line amplitude of line current to reduces the line loss and hence to improve the power quality.

Keywords: Sinusoidal line current, PWM rectifier, power factor, power quality.
\end{abstract}

\section{Introduction}

Recently, developments in power electronics and semiconductor technology have lead improvements in power electronic systems [1]. Today voltage and current source inverter are widely used in electrical motor drives. In this drives, DC voltage or current are usually obtained by using rectifiers with phase control and line commutation converters $[2,3]$. A three-phase AC to DC converter is often used to obtain a DC supply from three phase AC mains. Typical applications are UPS, battery charger, static frequency changer, motor drives etc. As this type of converter is normally connected at the front end / utility end of most of the power electronic systems, these are also called the front-end converter (FEC). The front end converter is designed to convert input ac power into intermediate dc Power. This type of rectifiers is the most used method in industrial applications. For three-phase, three-level rectifier systems a control of the input phase currents and of the output voltage has to be provided. Now a day's reactive power is the main problem for power quality improvement. Power factor improvement is the best solution to improve the power quality $[4,5]$. Any power problem manifested in voltage, current, or frequency deviations that result in failure or misoperation of customer equipment. We can make the power factor as unity by means of making the system voltage and current in phase. In this paper let us discuss about how we can make the system voltage and current are in phase with each other $[6,7]$.

\section{Circuit Description}

Circuit model of PWM rectifier is shown in Fig.1. This consists of three phase ac source, PWM rectifier, dc link capacitor and load. The input power is at $415 \mathrm{~V}, 3$ phase, $50 \mathrm{~Hz}$.

For closed loop operation the voltage and current controllers are used to get feedback voltage from the load side capacitor and to get current feedback from the source side inductor. The objectives of the control are as follows. 1. Control the de link voltage to pre-determined voltage ( $750 \mathrm{~V}$ in this application).

2. Control the input ac phase currents (Iac) to have a nearly sinusoidal wave shape and also in phase with the ac phase voltages.

3. Control the magnitude of the ac phase current to match the load on the dc bus.

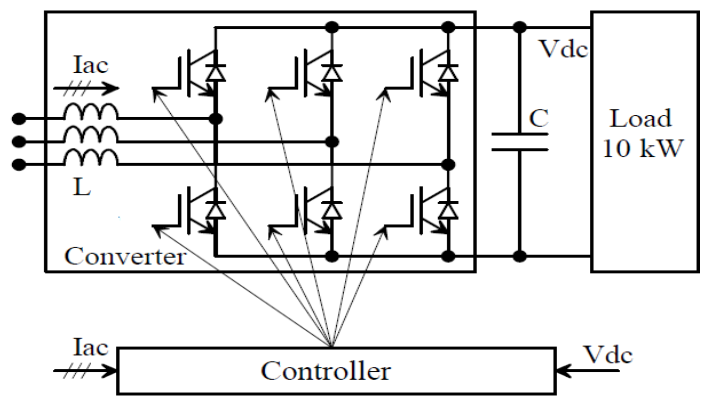


Fig. 1 Circuit model of the three phase PWM rectifier

From the circuit model of this three phase PWM rectifier the MATLAB/Simulink model was designed and its performance was analyzed.

\section{Three Phase To Two Phase Transformation}

The system being balanced, just two parameters can define it completely rather than three parameters $\left(\mathrm{V}_{\mathrm{a}}, \mathrm{V}_{\mathrm{b}}, \mathrm{V}_{\mathrm{c}}\right)$ as given above. Knowing any two of $\left(\mathrm{V}_{\mathrm{a}}, \mathrm{V}_{\mathrm{b}}, \mathrm{V}_{\mathrm{c}}\right)$ we can always write down the third one since $\mathrm{V}_{\mathrm{a}},+\mathrm{V}_{\mathrm{b}}+\mathrm{V}_{\mathrm{c}}=0$ (Though a sinusoidal system is considered here for simplicity, any non-sinusoidal balanced three phase system can be represented by just two parameters). This fact that two parameters are enough to describe a balanced three phase system should be convincing enough to accept the transformation of a three phase balanced system $(a, b, c)$ to a two axis system $(\alpha-\beta)$ as shown in Fig. 2

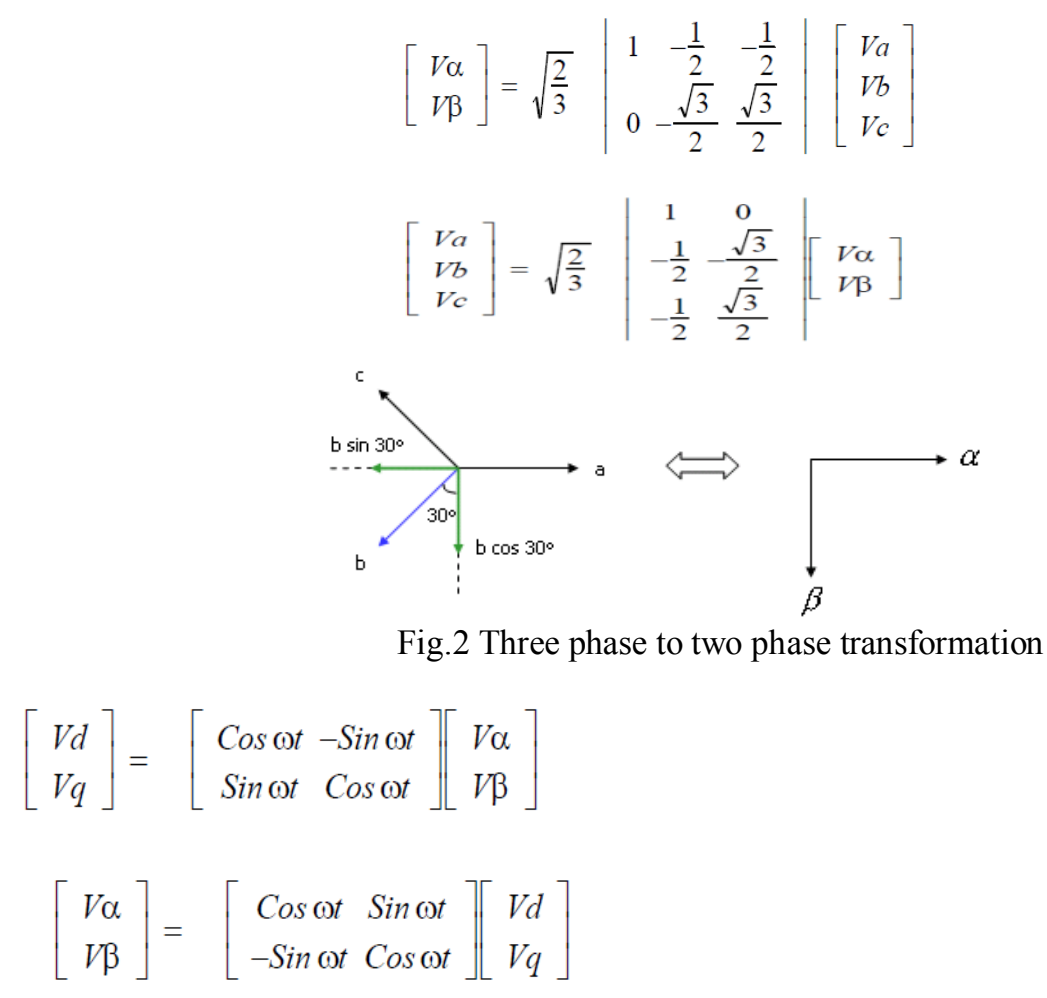

By using above equations the three phase ac voltage is converted into two phase direct and quadrature axis voltage and the two phase direct and quadrature axis voltage is converted into three phase ac voltage. In this way the three phase to two phase transformation is done.

\section{Pi Controller}

Today, a number of different controllers are used in industry and in many other fields. In quite general way those controllers can be divided into two main groups:

- $\quad$ conventional controllers - P, PI, PID - need mathematical modeling

- $\quad$ unconventional controllers - Fuzzy, neural....don't need modeling of the plant

Here the PI controller is used for the control of input current and output voltage. A proportional controller (P) reduces error responses to disturbances (transients), but still allows a steady-state error. When the controller includes a term proportional to the integral of the error (I), then the steady state error to a constant input is also eliminated, although typically at the cost of deterioration in the dynamic response. Dynamic response is defined as the output overshoot that occurs when the converter output load is turned on/off or abruptly changed.

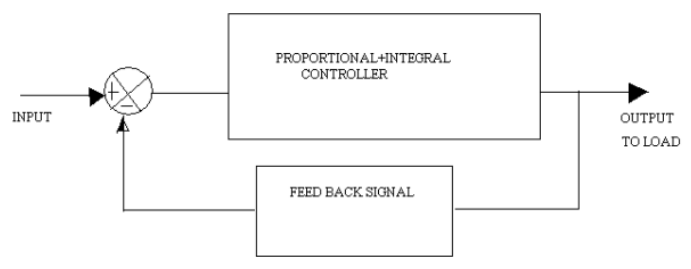


Fig.3 Structure of PI controller

For efficient operation Voltage and current PI controllers are used for controlling the input current and output voltage. From the controller and system transfer function the proportional and integral gain of the PI controller are calculated

$$
\begin{aligned}
& k_{p}=L / t \\
& k_{i}=R / t
\end{aligned}
$$

Here L represents the current controlled reactor and $\mathrm{R}$ represents the voltage sensing resistor. The overall current controller time constant ' $t$ ' is related to the cut-off frequency (' $\omega$ ' in radians) by the relationship $t=1 / \omega$

\section{Simulink Model}

Fig 4 shows the simulation model of the three phase PWM rectifier

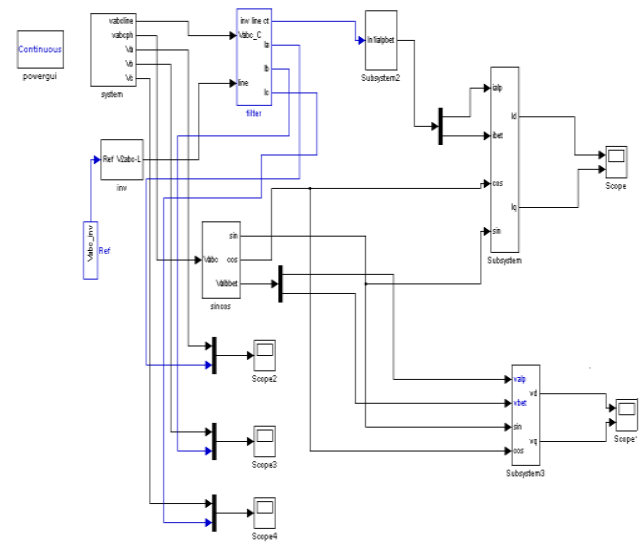

Fig.4 Simulation model of the PWM rectifier

Mathematical modeling of three phase PWM rectifier is shown in Fig. 4. Sin PWM technique is used to generate gate pulse input for the inverter. System line voltage and inverter line voltage is given in to the filter from this we can obtain three phase inverter current $i_{a}, i_{b}, i_{c}$. This three phase current and voltage of the inverter is converted into two phase (direct \& qudrature) axis voltage and current.

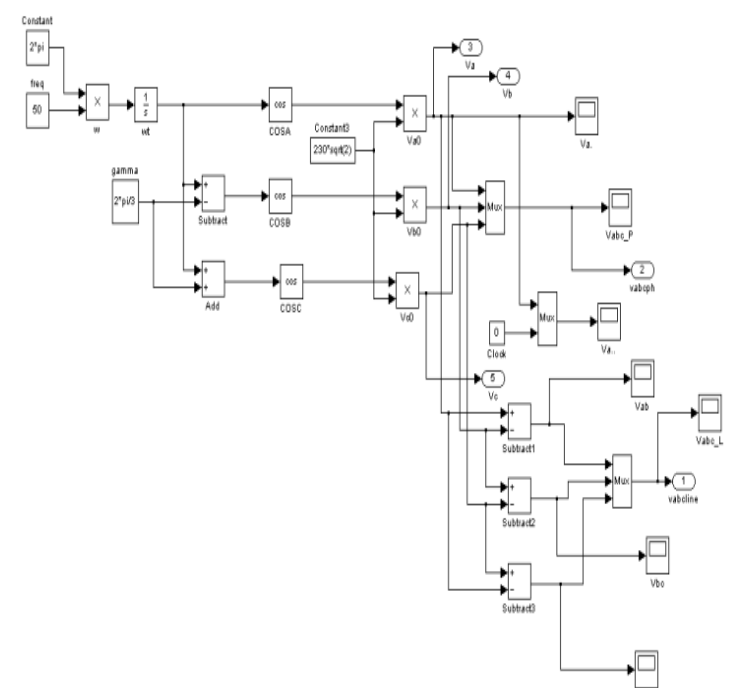

Fig.5 Simulation model of three phase voltage source

The above fig 5 shows the mathematical modeling of the three phase voltage source, which is present, in the subsystem of figure 4 . It consists of three phase system voltage $\left(V_{a}, V_{b}, V_{c}\right)$. 


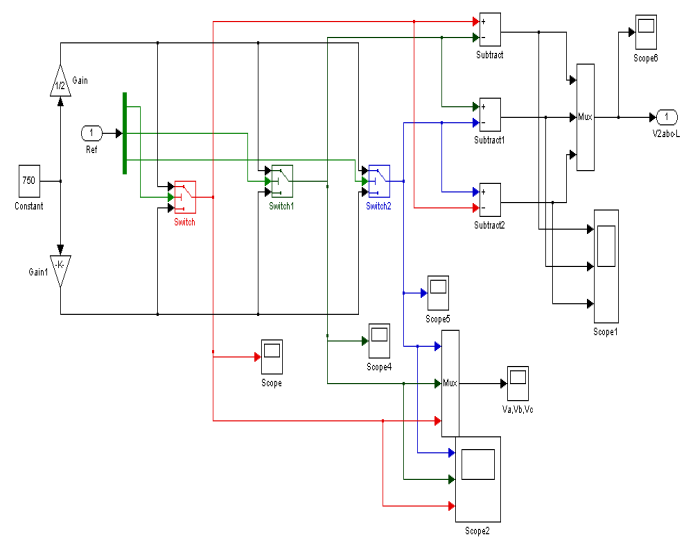

Fig.6 Mathematical modeling of the inverter

From the above fig 6 shows the mathematical modeling of the inverter, which is in the subsystem of the three phase PWM rectifier simulation model. From the above mathematical modeling three phase voltages of the inverter is obtained.

\section{Simulation Results}

To study the operation of the three phase PWM rectifier, it is implemented in SIMULINK/MATLAB environment. The simulation results obtained for different conditions and shown in fig.7 to 11

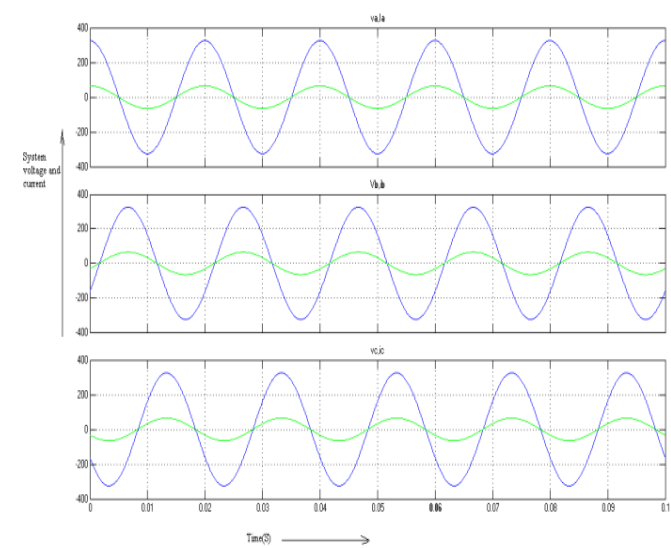

Fig. 7 Line current and Line to neutral voltage of the system

The above figure 7 shows the system voltage and current waveform. From this we can know the system voltage and current are inphase, which denotes the power factor is unity. From the above waveform we can identify there is no phase difference between voltage and current but their magnitudes are differ.
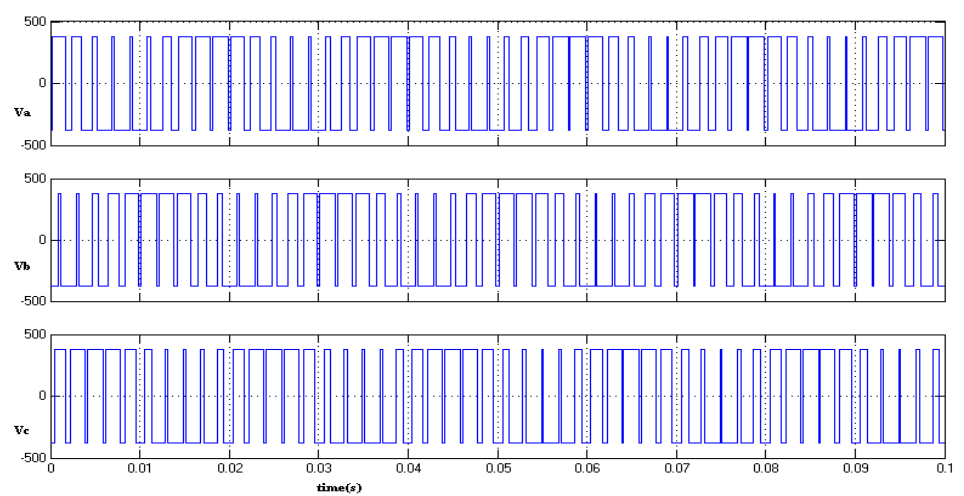

Fig. 8 The inverter line voltage waveform 
Fig 8 shows the line voltage waveform of the inverter. The sinusoidal PWM method is used to generate gating signal. This gating signal gives gate pulse to the gate terminals of the switches present in the inverter.

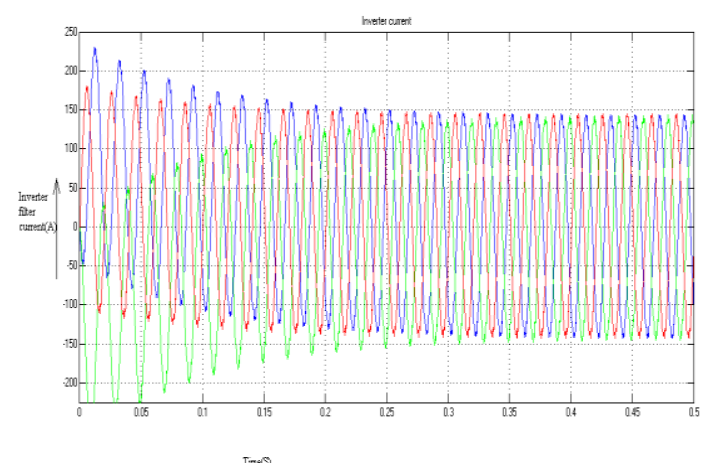

Fig.9 The inverter current wave form from the filter

Fig 9 shows the $i_{a}, i_{b}, i_{c}$ current from the filter. Filter compares the system voltage with the inverter voltage and from which the inverter current is obtained.

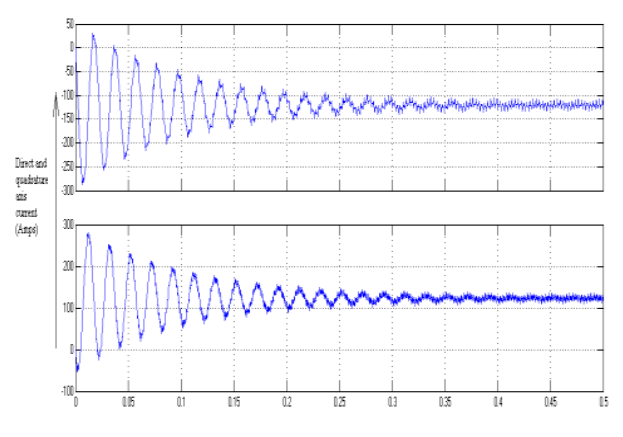

Fig.10 The direct and quadrature axis current waveforms

Fig 10 shows the direct and quadrature axis current waveforms of the three phase PWM rectifier.
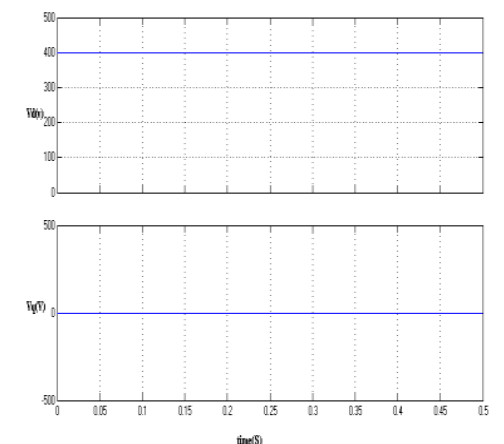

Fig.11 The direct and qudrature axis voltage waveforms

Fig 11 shows the direct and quadrature axis voltage waveforms. From this we can know the d axis i.e. the real power axis voltage is constant and the q axis i.e. the reactive power axis voltage is zero, which represents the power factor will be in unity.

\section{Hardware Analysis}

The hardware setup of the three phase PWM rectifier is shown in below figure. Which consists of multi input power supply circuit, bridge rectifier circuit, power circuit, FPGA controller circuit, MOSFET driver circuit, Zero crossing detector circuit etc. from the hardware circuit the phase voltage and current wave will be obtained by using CRO. 


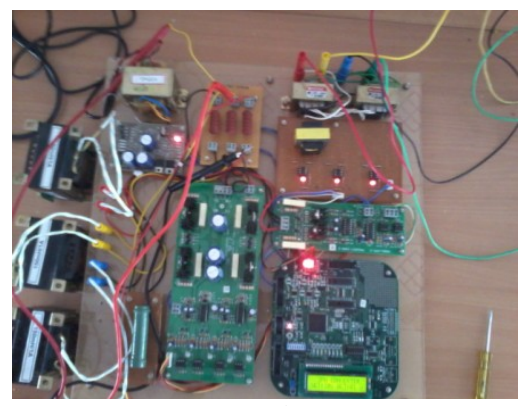

Fig 12: Hardware arrangement for three phase PWM rectifier

The hardware output for the three phase PWM rectifier is shown in below figure. The result has been seen through the CRO. From which we can know the source voltage and current are inphase. There is no lagging or leading between this two waveform. This shows the power factor is unity.

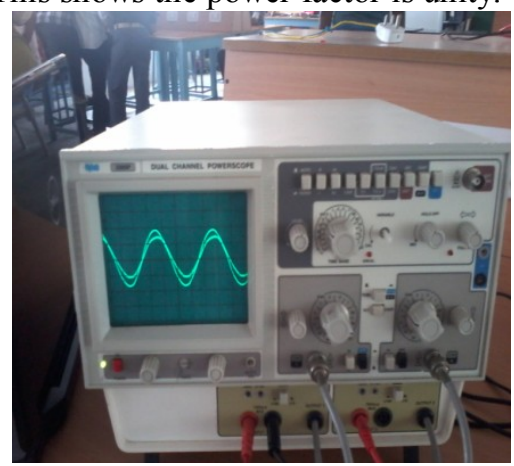

Fig.13 supply voltage and current waveform in same phase

\section{Conclusion}

In this paper three phase PWM rectifier was designed and its performance has been analyzed using Simulink/MATLAB package program. Simulation results have been given for power quality improvement by means of making qudrature axis voltage zero. If the quadrature axis voltage zero means the reactive power output from the source will be zero. This will lead to the system voltage and current within phase. If the voltage and current are in phase means the power factor will be unity. It was done in this paper. This will help in many industrial and drive applications.

\section{References}

[1]. V.Ramanarayanan, "Unity power factor front end rectifier for three phase input," Indian Institute of science, Switched mode power conversion $3^{\text {rd }}$ edition, p.no185-195, dec 2007.

[2]. T.Mahalekshmi, "Current Harmonic Compensation and Power Factor Improvement by Hybrid Shunt Active Power Filter" International Journal of Computer Applications (0975 - 8887) Volume 4 - No.3, July 2010.

[3]. Marian P.Kazmierkowski, "Control strategies for PWM rectifier/inverter-fed induction motors", IEEE conference, Volume: 1, Page(s): TU15 -TU23 vol.1, june2000.

[4]. M. Malinowski, M.P. Kaźmierkowski, S. Hansen, F. Blaabjerg, G. D. Marques, .Virtual flux based Direct Power Control of threephase PWM rectifier., IEEE Trans. on Ind. Applications, vol. 37, no. 4, pp. 1019-1027, Jul/Aug 2001.

[5]. T.G.Subhash Joshi, Aby Joseph and Gautam Poddar, "Active power factor correction for highly fluctuating industrial load", NPEC, 2003

[6]. Ned Mohan, Tore M. Undeland, William P. Robbins, "Power Electronics: Converters, Applications, and Design", John Wiley \& Sons, Inc, $3^{\text {rd }}$ Ed., 2003

[7]. H. Sarén, "Analysis of the voltage source inverter with small dc-link capacitor," Ph.D. thesis, Lappeenranta Technical University, 2005.

[8]. Power Electronics book by Dr. P.S. Bimbhra. Khanna Publishers, New Delhi, 2003. 3rd Edition.

[9]. A Power Electronics Handbook by M.H. Rashid. Academic Press 2001.

\section{Bibliography}

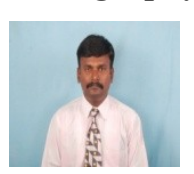

P. Manikandan is a Asstant Professor and Head of EEE department of Sree Sowdambika College of Engineering, Aruppukottai. He Completed his UG in Electrical \& Electronics Engineering at Arulmigu Kalasalingam College of Engineering in the year of April 2003 and M.E Power System Engineering in the year 2005 at Annamalai University, Chidambaram. He have registered for Ph.D on July 2011 in the field of Renewable Energy at Anna University of Technology Tirunelveli. His areas of research include renewable energy, Power Electronics and FACTS. His research title is Long-term reserve planning of power system with High wind power penetration using universal 
generating function methods. He has 2 publications in his research area. He is life member of ISTE and IETE. He has written a text book of Measurement \& Instrumentation in Anuradha Publications, Chennai.

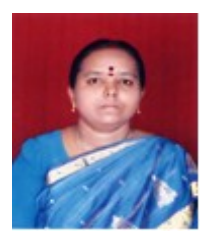

Dr.SP.Umayal is a professor and head of power electronics and drives engineering of sethu institute of technology, Kariapatti.She completed her U.G in Electrical and Electronics Engineering at thiagarajar college of Engineering in the year of 1990 and M.E power system in the year 1999 in the same institution. She received her Ph.D in the year 2008 in the field of Power System Optimization. Her areas of research include Power system optimization, FACTS and power quality. She has 35 publications in her research area. Presently she is guiding 10 M.E researchers and 5 Ph.d. scholars. She is the life member of IE (I) and ISTE.

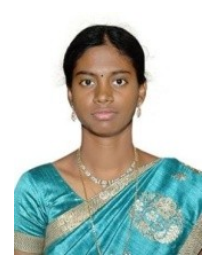

A.MARIYA CHITHRA MARY is a Asstant Professor of EEE department of Sree Sowdambika College of Engineering, Aruppukottai. She completed her UG in Electrical \& Electronics Engineering at Mepco schlenk engineering college in the year of April 2011 and M.Tech Power electronics in the year 2013 at Kalasalingam University, Krishnankoil.

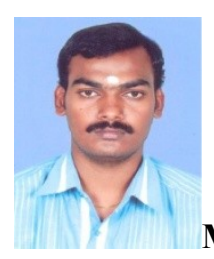

M.Ramachandran is a Assistant Professor of EEE department of PSN college of engineering and technology, Tirunelveli. He completed his UG in Electrical \& Electronics Engineering at Sree Sowdambika College of engineering in the year of April 2009 and M.E Power Management in the year 2013 at Anna University of technology, Madurai. 